Section Editor

Robert C. Griggs, MD
Editors' Note: Hung argues that the association between the HLA-B*1502 genotype and Stevens-Johnson syndrome (SJS)/toxic epidermal necrolysis (TEN) differs depending on whether patients are taking carbamazepine vs phenytoin and that cost estimates for the long-term sequelae of SJS/TEN are overlooked in the study by Dong et al. The authors explain the rationale of considering both drugs together and why the high cost of SJS/TEN treatment makes genotyping cost-effective. Droogsma and colleagues identify a potential selection bias in the study by Pariente et al., "Effect of treatment gaps in elderly patients with dementia treated with cholinesterase inhibitors," and suggest that clinicians should not discontinue treatment too readily as this may affect cognition.

Chafic Karam, MD, and Robert C. Griggs, MD

\section{COST-EFFECTIVENESS OF HLA-B*1502 GENOTYPING IN ADULT PATIENTS WITH NEWLY DIAGNOSED EPILEPSY IN SINGAPORE}

Shuen-Iu Hung, Wen-Hung Chung, Taipei, Taiwan: Dong et al. ${ }^{1}$ reported that HLA-B*1502 genotyping is cost-effective in preventing both carbamazepine (CBZ) - and phenytoin (PHT)-induced StevensJohnson syndrome (SJS)/toxic epidermal necrolysis (TEN) in Singaporean Chinese and Malays. However, we would like the authors to consider some issues. First, HLA-B*1502 genetic association with PHT-SJS/TEN is not strong enough to be clinically valuable compared with CBZ, although CBZ and PHT are structurally similar with a potential cross-hypersensitive reaction. ${ }^{2-4}$ In our large-scale study, HLA-B*1502 was present in only $30.8 \%$ (8/26) PHT-SJS/TEN compared to 8\% (9/ 113) PHT-tolerant controls (odds ratio $5.1 ; 95 \%$ confidence interval $1.8-15.1 ; p=0.0041) .{ }^{3}$ Almost $70 \%$ of PHT-SJS/TEN patients cannot be predicted by HLA$\mathrm{B}^{*} 1502$ genotyping even in Chinese patients so the costeffectiveness analysis for PHT should be separated. Secondly, cost estimates for the long-term sequelae of SJS/TEN were overlooked. The authors based costs on the discharge data of 20 cases without follow-up. In our previous study of antiepileptic druginduced SJS/TEN, 22.08\% of cases developed eye complications and required long-term treatment after
WriteClick: Editor's Choice

the discharge. The long-term medical care for sequelae of SJS/TEN was the most expensive part. ${ }^{5}$

Author Response: Di Dong, Cynthia Sung, Andrew Finkelstein, Singapore: We thank Hung et al. for their comments. We acknowledge that our model was populated largely based on CBZ-SJS/TEN. We modeled CBZ and PHT together because both drugs are used interchangeably in Singapore as first-line drugs for epilepsy. In addition, both drugs have a significant association with SJS/TEN in HLA-B*1502 carriers. However, as Hung et al. correctly indicate, the magnitude of the effect is much lower for PHT. The model is flexible and if data are available, it would be helpful to conduct separate analyses for PHT as suggested. We also recognize the importance of future research to better characterize the genetic risk factors for PHT-SJS/ TEN.

Some patients will have eye complications ranging from dry eye syndrome to blindness, which would incur long-term costs. Occasionally, very sophisticated and expensive procedures such as osteo-odonto-keratoprosthesis have restored vision for SJS/TEN patients in Singapore. To simplify, we did not model long-term eye-related complications. Instead, we modeled a lump sum cost, which we assume can represent the present value of long-term costs, and conducted sensitivity analysis to examine the influence of the SJS/TEN management cost on incremental cost-effectiveness ratio. As our sensitivity analysis showed, a higher cost for SJS/ TEN treatment strengthens the conclusion that genotyping is cost-effective.

(C) 2013 American Academy of Neurology

1. Dong D, Sung C, Finkelstein EA. Cost-effectiveness of HLA-B*1502 genotyping in adult patients with newly diagnosed epilepsy in Singapore. Neurology 2012;79: 1259-1267.

2. Hung SI, Chung WH, Jee SH, et al. Genetic susceptibility to carbamazepine-induced cutaneous adverse drug reactions. Pharmacogenet Genomics 2006;16:297-306.

3. Hung SI, Chung WH, Liu ZS, et al. Common risk allele in aromatic antiepileptic-drug induced Stevens-Johnson syndrome and toxic epidermal necrolysis in Han Chinese. Pharmacogenomics 2010;11:349-356.

4. Locharernkul C, Loplumlert J, Limotai C, et al. Carbamazepine and phenytoin induced Stevens-Johnson syndrome is associated with HLA-B*1502 allele in Thai population. Epilepsia 2008;49:2087-2091. 
5. Yang CY, Dao RL, Lee TJ, et al. Severe cutaneous adverse reactions to antiepileptic drugs in Asians. Neurology 2011;77: 2025-2033.

EFFECT OF TREATMENT GAPS IN ELDERLY PATIENTS WITH DEMENTIA TREATED WITH CHOLINESTERASE INHIBITORS

Erika Droogsma, Leeuwarden; N.J.G.M. Veeger, Groningen; P.E. van Walderveen, S.M. Niemarkt, D.Z.B. van Asselt, Leeuwarden, the Netherlands: Pariente et al. ${ }^{1}$ concluded that "Treatment gaps do not compromise the outcome of patients treated with cholinesterase inhibitors in a real-life setting." However, their conclusion is based on the effect of treatment gaps on risk of institutionalization and death, rather than on disease-specific endpoints. It has been shown that the beneficial effect of cholinesterase inhibitors on cognition, an important disease-specific endpoint, disappears within 3 weeks of discontinuation. ${ }^{2,3}$ In addition, as mentioned by Pariente et al., treatment gaps are likely to occur in patients in whom reinitiation of treatment is worthwhile. From this, we infer that selection may have played a role, consequently limiting the generalizability of the study to a real-life setting. ${ }^{4}$ This study is welcome because the authors address an important issue. However, because of these caveats, clinicians should not discontinue treatment too readily, as discontinuation of treatment does affect cognition, thereby compromising the outcome of patients.

(C) 2013 American Academy of Neurology

1. Pariente A, Fourrier-Réglat A, Bazin F, et al. Effect of treatment gaps in elderly patients with dementia treated with cholinesterase inhibitors. Neurology 2012;78:957-963.

2. Greenberg SM, Tennis MK, Brown LB, et al. Donepezil therapy in clinical practice: a randomized crossover study. Arch Neurol 2000;57:94-99.

3. Gaudig M, Richarz U, Han J, et al. Effects of galantamine in Alzheimer's disease: double-blind withdrawal studies evaluating sustained versus interrupted treatment. Curr Alzheimer Res 2011;8:771-780

4. Stang A. Appropriate epidemiologic methods as a prerequisite for valid study results. Eur J Epidemiol 2008;23:761-765.

\section{Neurology ${ }^{\circledR}$ WriteClick: Join the Debate!}

The editors encourage comments about recent articles through WriteClick:

Go to www.neurology.org and click on the "WriteClick" tab at the top of the page. Responses will be posted within 72 hours of submission.

Before using WriteClick, remember the following:

- WriteClick is restricted to comments about studies published in Neurology within the last eight weeks

- Read previously posted comments; redundant comments will not be posted

- Your submission must be 200 words or less and have a maximum of five references; reference one must be the article on which you are commenting

- You can include a maximum of five authors (including yourself) 


\title{
Neurology
}

\author{
Cost-effectiveness of HLA-B*1502 genotyping in adult patients with newly diagnosed \\ epilepsy in Singapore \\ Shuen-Iu Hung and Wen-Hung Chung \\ Neurology 2013;80;1621-1622 \\ DOI 10.1212/WNL.0b013e3182915be2
}

\section{This information is current as of April 22, 2013}

Updated Information \& Services

References

Permissions \& Licensing

Reprints including high resolution figures, can be found at: http://n.neurology.org/content/80/17/1621.full

This article cites 5 articles, 2 of which you can access for free at: http://n.neurology.org/content/80/17/1621.full\#ref-list-1

Information about reproducing this article in parts (figures,tables) or in its entirety can be found online at:

http://www.neurology.org/about/about_the_journal\#permissions

Information about ordering reprints can be found online:

http://n.neurology.org/subscribers/advertise

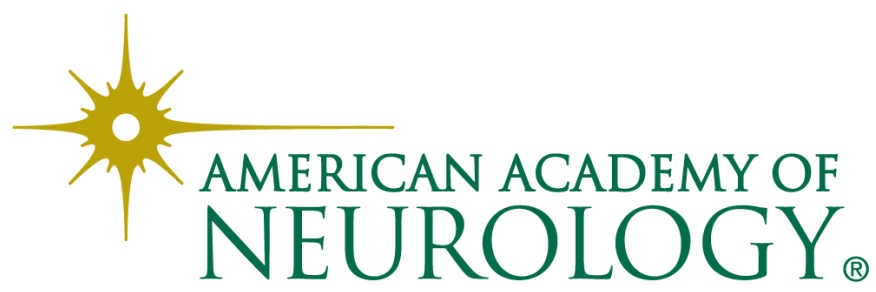

